\title{
Extreme Loads Estimation for a Prospective Offshore Wind Farm Site in Puerto Rico
}

\author{
Raúl Valerio, MS student ${ }^{1}$, and José A. Santiváñez, Ph.D. ${ }^{2}$ \\ ${ }^{1}$ Universidad de Puerto Rico-Mayagüez, Puerto Rico, raul.valerio@upr.edu \\ ${ }^{2}$ Universidad del Turabo, Puerto Rico, santivanezj@suagm.edu
}

\begin{abstract}
This study consists in estimating long term weather characteristics and predicting extreme loads for a prospective offshore wind site located in the Puerto Rico archipelago. This location has been described in a recent study as the best possible area for wind energy generation in Puerto Rico. Regretfully, available field weather data for the target site is limited, which poses a challenge for insufficient for most statistical forecasting techniques. In order to overcome data scarcity in target location, two different approaches are used: (1) Measure-Correlate-Predict (MCP) methods, where long term data in nearby weather buoys are used to estimate long term wind characteristics in target site, and (2) Statistical extrapolation techniques, where distributions for the extreme mudline bending moment are established using parametric models as functions of wind speed and wave height in the target site to predict extreme loads, where fifty-years return loads are estimated. Finally, we discuss advantages and limitations using these techniques in target site based in data sets currently available.
\end{abstract}

Keywords-Measure-Correlate-Predict, Extreme Loads, Statistical Extrapolation, Offshore Wind Farms.

\section{INTRODUCTION}

There is a before and after in the history of Puerto Rico due to Hurricane Maria, a category 5 tropical cyclone that became a catastrophe in the Caribbean Sea. Maria made landfall in Yabucoa, Puerto Rico as a strong category 4 hurricane on the island on September 20, 2017 [1].

The Federal Emergency Management Agency (FEMA) published some statistics comparing the signs of recovery in Puerto Rico by numbers of days after Maria made landfall [2]. In this summary, we can see that 30 days after the atmospheric phenomenon only $21 \%$ of the power generation was working and even 120 days later only $80.3 \%$ of the service had been restored, in addition the number of generators had increased from 148 to 708 in a 3-month interval.

Hurricane Maria and Hurricane Irma demonstrated the weakness of the Puerto Rican electrical system where its grid is sensitive to falls and not resistant to the onslaught of intense winds or continuous rains. Therefore, it is inevitable to think about how to improve or renew the distribution, generation and infrastructure of the power grid as it was discussed by Greenemeier [3]. Identically, PREPA plan's mention of distributed generation is an appreciation the island needs more generators positioned throughout the island.

It is known the Puerto Rico Electric Power Authority is expecting to generate over $380 \mathrm{MW}$ from wind sources but none of the existing or future projects consider an offshore wind energy farm as it is discussed in [4].

A 2010 law in PR established that 12\% of the energy produced must be generated through renewable sources by 2015 and shall increase to $15 \%$ by 2020 and $20 \%$ by 2035 [5]. But currently less than $2 \%$ is generated by renewable sources.

The potential benefits for offshore wind energy in PR were recognized in a University of Puerto Rico study in 2008 [6] where they showed the best wind resources are in northern and eastern ocean areas, later considered in a Universidad del Turabo study in 2016 [7] to select the best possible offshore wind turbine location.

Our target station is located in Vieques Island, PR and it is owned and maintained by Caribbean Integrated Coastal Ocean Observing System (CarICOOS) [8] with station number 41056 $(18.260 \mathrm{~N} 65.457 \mathrm{~W})$. And for reference station we chose Station 61019 (19 N 66 W) managed by US Army Corps of Engineers in their project Wave Information Study (WIS) [9]. This station is taken under consideration because it consists of 35 years of hind cast data sets representing the far field around Puerto Rico.

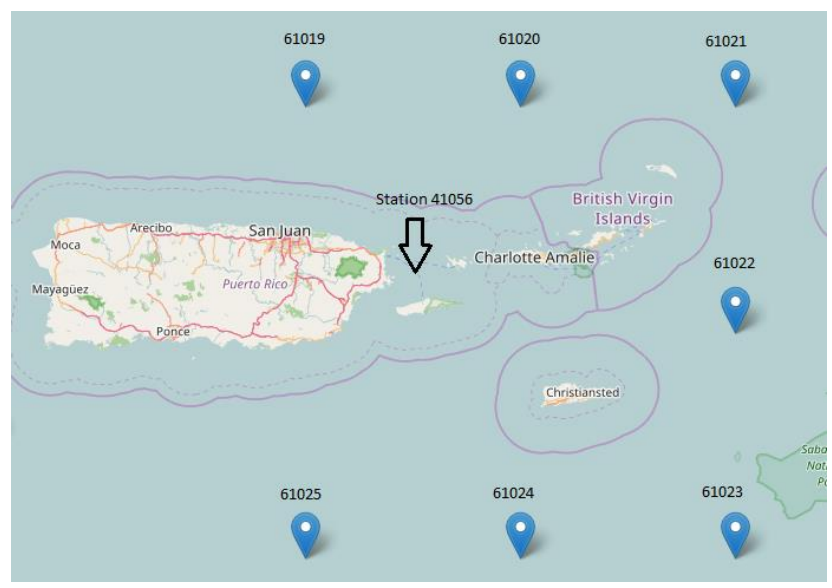

Fig. 1 Target station and reference station [9].

Given that Puerto Rico is threatened by storms or hurricanes because of its geographical location and the complexity of installations, it is of the utmost importance to estimate extreme loads for the target site before building up the wind farm. 


\section{METHODOLOGY \\ Objectives}

The objective for using Measure-correlate-predict (MCP) methods is to carry out long-term hindcasting of the wind conditions at a candidate site for which only short-term wind data series are available.

Additionally, one of our goals is to compare recent events with historic data to establish some expected extreme load values. Considering the recent disasters that have occurred in the area, we will compare predicted maximum values and maximum values that have occurred in past months.

Similarly, we aim to describe and analyze some important statistics related to the target site using predicted time series data to explain the characteristics of our proposed target site.

Using statistical extrapolation techniques, we will calculate the target failure probability associated with service life and to estimate long-term extreme loads that could occur in the place of interest. In addition, model for a short term the parametric density distribution associated with environmental variables behavior.

\section{A. Measure-Correlate-Predict}

\section{Considerations}

MCP methods were used to model the relationship between wind data (speed and direction) measured at the target site, and at the reference site for a period more than 1 year (15 months). Data sets with long-term data from the reference site (a period of more than 30 years, 1980 - 2014) were used to predict the long-term wind speed and direction distributions at the target site.

According to ref [10] it is said that the coefficient of determination $\left(R^{2}\right)$, the ratio between variability explained and total variability in the regression, should not be lower than $70 \%$ to consider the results as acceptable.

Similarly, based in [10] if the correlation coefficients range between $0.6-0.7,0.7-0.8,0.8-0.9$, and $0.9-1.0$ are considered poor, moderate, good and very good, respectively.

\section{Methods and equations}

Seven MCP methods were considered in this study:

- Method of ratios (single sector): uses the ratio of short term wind speed means between target site

$$
\left(v_{j}^{L T}\right)_{t}=\left[\frac{\bar{v}_{t}^{S T}}{\bar{v}_{r}^{S T}}\right] *\left(v_{j}\right)_{r}^{L T}
$$

- Method of ratios (multiple sectors): The ratio of means with multiple sectors method differs from the single sector version in that it tries into account the influence of the wind direction and for that and for that purpose uses a ratio for each of the $\mathrm{N}$ sectors of $\theta^{\circ}$ that can defined in relation to the direction sector, $\left(\theta_{k}\right)_{r}$, of the reference site.

- Variance ratio: Rogers et al. [11] propose using the socalled variance ratio method, to predict the long-term wind speed at a target site:

$$
\left(v_{j}^{L T}\right)_{t}=\left[\bar{v}_{t}^{S T}-\frac{s_{t}^{S T}}{s_{r}^{S T}} \bar{v}_{r}^{S T}\right]+\frac{s_{t}^{S T}}{s_{r}^{S T}} *\left(v_{j}\right)_{r}^{L T}
$$

- Simple linear regression (SLR): also known as straight line regression as it is proposed at [12].

$$
\left(v_{j}^{L T}\right)_{t}=\bar{v}_{t}^{S T}+r^{S T} * \frac{s_{t}^{S T}}{s_{r}^{S T}} *\left[\left(v_{j}\right)_{r}^{L T}-\bar{v}_{r}^{S T}\right]
$$

- Multiple Simple linear regression: Most MCP methods use a single reference station, but here we estimated the wind characteristics using 6 reference stations to build a linear model. We used LASSO from package glmnet [13] in R() to select the best model. WIS stations 61019 to 61025 were used in this method.

- Method of bins: the wind speed data are grouped into bins of wind speed and wind direction sectors. In this case, the wind speeds of the target station are binned versus the binned measured wind speeds of the reference station in ranges of $0.5 \mathrm{~m} / \mathrm{s}$.

$$
\begin{gathered}
\left(v_{i}^{L T}\right)_{t}= \\
\left(\bar{v}_{b}\right)_{t}^{S T}+\left[\left(v_{i}\right)_{r}^{L T}-\left(\bar{v}_{b}\right)_{r}^{S T}\right] \frac{\left(\bar{v}_{b+1}\right)_{t}^{S T}-\left(\bar{v}_{b}\right)_{t}^{S T}}{\left(\bar{v}_{b+1}\right)_{r}^{T}-\left(\bar{v}_{b}\right)_{r}^{S T}}
\end{gathered}
$$

- Principal component analysis: PCA is a statistical method used to reduce the number of variables in a dataset. We use wind speed and wind direction to create a time-delay matrix and then apply a Singular Value decomposition: $Y=P \Delta S$. This method is described in ref [14].

$1^{\text {th }}$ LACCEI International Multi-Conference for Engineering, Education, and Technology: "Innovation in Education and 


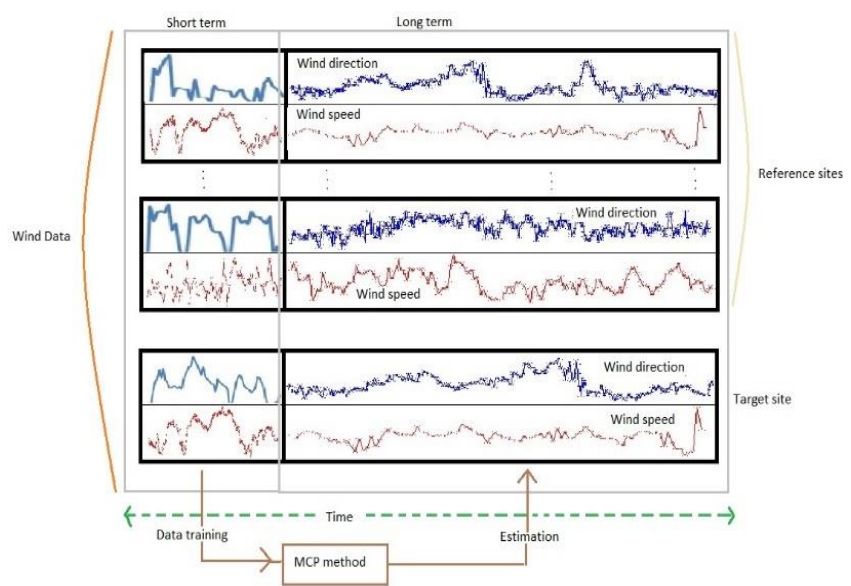

Figure 2 Block diagram for MCP methods procedure [10]

\section{B. Statistical Extrapolation}

\section{Environmental considerations}

According to Agarwal [15] the appropriate long-term load, $l_{T}$, corresponding to a service life of $T$ years (usually 20 years) needs to be determined by consideration of the probabilistic distribution for all important environmental random variables, as well as for the turbine load conditional on the environment.

The turbine under consideration is defined by the $10 \mathrm{~min}$ mean wind speed at the $90 \mathrm{~m}$ (possible turbine nacelle height), denoted by the random variable $V$, and the significant wave height, denoted by $H_{s}$ measured every hour. The variables $H_{s}$ and $V$ are modelled as jointly distributed random variables.

For the statistical load extrapolation 4 years and 2 months of data sets available were used to calculate the appropriate long-term load $l_{T}$. From October $1^{\text {st }} 2013$ to December $31^{\text {st }}$ 2017, covering the Hurricane María and Hurricane Irma events.

\section{Equations and distributions}

- The turbine load of interest, $L$, depends on $V$ and $H_{s}$, and is thus an implicit function of the environmental random variables. For the target failure probability, $P_{T}$, associated with the service life, $T$, we are interested in estimating $l_{T}$ such that:

$P_{T}=P\left[L>l_{T}\right]=$

$\iint_{H_{S}, V} P\left[L>l_{T} \mid\left(V, H_{s}\right)\right] f_{V, H_{S}}(v, h) d v d h$

where $f_{V, H_{S}}(v, h)$ is the joint probability density function of the environmental random variables.

- We assume that the random variable, $H_{S}$, the significant wave height, conditional on the mean wind speed, V, follows a Weibull distribution. The expression for the CDF of $H_{s}$ conditional on $\mathrm{V}$, namely $F_{H_{S} \mid V}(h)$ is given by:
$\boldsymbol{F}_{\boldsymbol{H}_{\boldsymbol{S}} \mid \boldsymbol{V}}(\boldsymbol{h})=1-\exp \left(-\left(\frac{h}{\eta(v)}\right)\right)^{k(v)}$

Both the shape, $\mathrm{k}$, and the scale parameter, $\eta$, of the Weibull distribution depend on the mean wind speed.

- The mean wind speed, $V$, follows a Rayleigh distribution, but our interest is to study loads that arise when the turbine is operating then the Rayleigh distribution is truncated below $V_{\text {in }}$ of $4 \mathrm{~m} / \mathrm{s}$ and above $V_{\text {out }}$ of $25 \mathrm{~m} / \mathrm{s}$. The truncated cumulative distribution $(\mathrm{CDF}), F_{v}(v)$, of $\mathrm{V}$ is:

$$
F_{v}(v)=\frac{G\left(V_{\text {in }}\right)-G(v)}{G\left(V_{\text {in }}\right)-G\left(V_{\text {out }}\right)} ; \text { with } G(v)=\exp \left(-\left(\frac{v}{\alpha}\right)\right)^{2}
$$

where $\alpha$ is Rayleigh distribution parameter to be estimated from the average value of $V$.

- $\quad$ To represent the random variable $L$, the twoparameter Gumbel distribution conditional on the variable $V$ and $H_{s}$ is chosen. The cumulative distribution for $\mathrm{M}$ is given by:

$F_{M \mid V, H_{S}}(m)=\exp \left(-\exp \left(-\frac{m-u(v, h)}{\beta(u, v)}\right)\right)$

The Gumbel parameters, $\mu$ (modal value) and $\beta$ (measure of dispersion), are dependent on $V$ and $H_{s}$, and were evaluated from the available $\left(V, H_{s}\right)$ data. The data are binned into $\left(V, H_{s}\right)$ cells and the parameters, $\mu$ and $\beta$, are estimated for each cell. A cell size of $1.5 \mathrm{~m} / \mathrm{s}$ in the $V$ direction and $0.3 m$ in the $H_{s}$ direction is used in this study.

- $\quad$ Because we are dealing with numerical data, the total probability is finally obtained by adding the contributions of all the cells, instead of the integral formula, as expressed in the following double sum:

$P_{T}=P\left[L>l_{T}\right] \approx$

$\sum_{i=1}^{N_{v}} \sum_{j=1}^{N_{H}}\left[1-F_{L \mid V, H_{S}}\left(l_{T}\right) \mid v_{i}, h_{j}\right] f_{V, H_{S}}(v, h) \Delta V \Delta H_{S}$

\section{RESULTS}

\section{A. Measure-Correlate-Predict}

Before applying the MCP methods we dealt with the wind speed height correction given that target station wind speed was measured at $4 \mathrm{~m}$ and reference station at $10 \mathrm{~m}$.

This is, using the formula of Wind Speed Height Correction as shown in equation (10) according to ref [6]. 


$$
\frac{v\left(h_{1}\right)}{v\left(h_{2}\right)}=\left(\frac{h_{1}}{h_{2}}\right)^{\alpha}
$$

Where $v\left(h_{1}\right)$ is the wind speed at the desired height $h_{1}$, $v\left(h_{2}\right)$ is the wind speed measured at reference height $h_{2}$. A commonly used value for $\alpha$ is $1 / 7$.

Then, using some steps to pair the 10 minutes average wind speed at 10 meters for target station and 1 hour wind speed at 10 meters for reference stations respectively for October 2013 and December 2014. This is, 10568 observations in that period.

First, we grouped the target station data by year, month, day and hour then we calculated the mean wind speed and mean wind direction by these factors.

Second, we created a table with both sets of data, the objective and the reference, merging them comparing year, month, day and hour. Finally, we could obtain that our target station and reference station have an initial Pearson's correlation $r$ of $69.7 \%$ during period of study. Given this and taking into account the initial considerations in paragraph $\mathrm{A}$, we must be cautious in our final predictions since $r$ is moderate result.

Once the methods are performed, we compared the goodness of fit for each model using the coefficient of determination $\mathrm{R}^{2}$ as comparative measure, finding out no more than $65 \%$ variability explained for any model as it is summarized in table 1 . Methods of single and multiple sectors, Variance ratio and Method of bins are the models with the best adjust.

As it is discussed before in the considerations paragraph A in the methodology section and last statement no method provides the desired accuracy to predict wind speed for longterm for the target site, also correlation $r$ was found out to be no greater than 0.73 . PCA improves linear regression a $17 \%$ as ref [14] said but not enough in this scenario.

The linear algorithm Multiple sectors histogram predictions is showed in Fig. 3, during the long-term period under study (1980 -2014). It is very easy to appreciate the shape of density with bias to the right, indicating that most of the wind speed is below $10 \mathrm{~m} / \mathrm{s}$.

\begin{tabular}{|l|c|l|}
\hline \multicolumn{1}{|c|}{ MCP method } & $R^{2}$ & $\mathrm{r}$ \\
\hline Single Sector (ratio) & 0.63 & 0.70 \\
\hline Multiple sector using Wind direction & 0.62 & 0.70 \\
\hline Variance ratio & 0.62 & 0.70 \\
\hline Simple linear Regression & 0.48 & 0.72 \\
\hline Method of Bin fitting & 0.63 & 0.70 \\
\hline Multiple Linear Regression & 0.51 & 0.71 \\
\hline PCA & 0.56 & 0.50 \\
\hline
\end{tabular}

Table 1 Summary MCP methods results

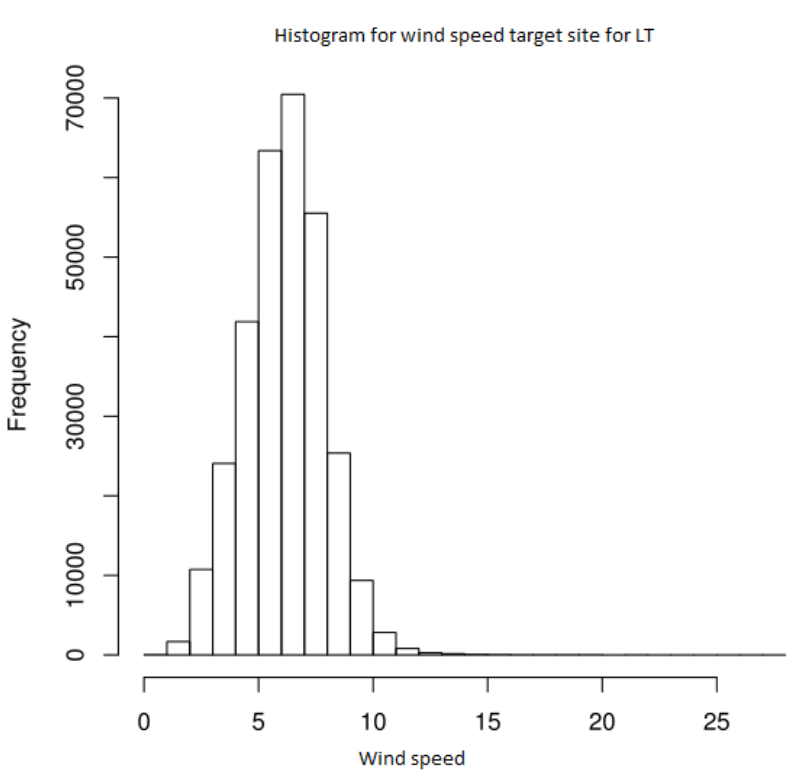

Fig. 3 Predicted long-term wind speed for a target site using multiple sectors method

In Fig. 4 we can observe predicted short-term wind speed density for target site using some MCP methods and checking how they fit during the short-term period of study. The blue line represents the actual values for the target station during the short-term period. We can observe that even with a $72 \%$ correlation the prediction of the Bin method does not fit the real density of the target site.

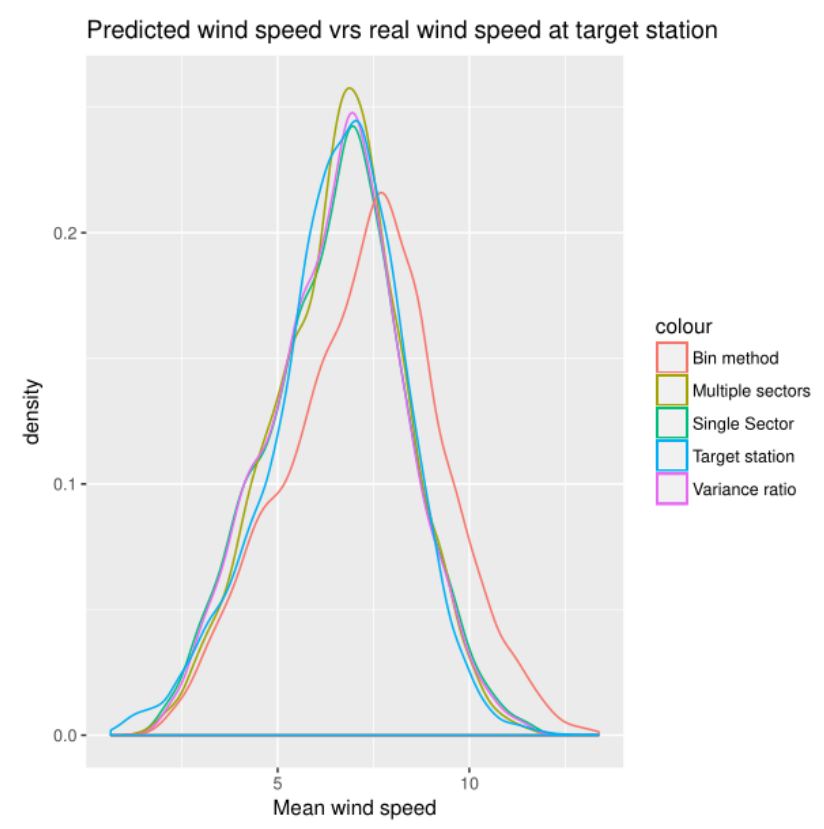

Fig. 4 Predicted short-term wind speed density for target site

16 $^{\text {th }}$ LACCEI International Multi-Conference for Engineering, Education, and Technology: "Innovation in Education and Inclusion", 19-21 July 2018, Lima, Peru. 
Based on those facts, Method of sectors, as well as Variance ratio are most appropriated method to describe our target site in long term period.

\begin{tabular}{|l|l|l|l|}
\hline Method & $\bar{v}_{t}^{L T}$ & $s_{t}^{L T}$ & $\begin{array}{l}\text { Maximum } \\
\text { expected } \\
\text { value }\end{array}$ \\
\hline Single sector & 6.056 & 1.81 & 25.27 \\
\hline $\begin{array}{l}\text { Multiple } \\
\text { Sector }\end{array}$ & 6.12 & 1.75 & 27.88 \\
\hline Variance & 6.067 & 1.77 & 24.86 \\
\hline Bin fitting & 6.73 & 2.02 & 28.28 \\
\hline
\end{tabular}

Table 2. Predicted long term values for target site.

Table 2 summaries some important statistics for predicted longterm wind speed at the target site. Using these values, we can say the coefficient of variation is around $30 \%$ for all MCP methods in table 2 . This means that there is very little homogeneity in the data, but this could be expected in a phenomenon like the wind. We used a Rayleigh density random generator and calculating $\alpha$ (see eq. 7) we were able to obtain the probability of having a wind speed higher than $28 \mathrm{~m} / \mathrm{s}$ and this was $0.02 \%$, in other words, it is unlikely that there were extreme wind speeds.

Having said that, during Hurricane Maria the maximum wind speed at $4 \mathrm{~m}$ values of up to $27.5 \mathrm{~m} / \mathrm{s}$ were recorded, this is, $31.35 \mathrm{~m} / \mathrm{s}$ to a $10 \mathrm{~m}$ height. That is, the highest predicted value with MCP methods was exceed by 3 units. However, during the period October $1^{\text {st }} 2013$ to December $31^{\text {st }} 2017$ the mean speed wind in target site was $6.53 \mathrm{~m} / \mathrm{s}$ with a standard deviation of 1.81 in a 1-hour average.

Therefore, it is not far from predicted characteristics with MCP methods.

\section{B. Statistical Extrapolation}

Initially, our data comes from a measurement at $4 \mathrm{~m}$ then as we did in MCP methods we used the formula of wind speed height correction from eq. (10) to convert it to our $90 \mathrm{~m}$ height.

The maximum mean wind speed recorded in the buoys was 27.5 $\mathrm{m} / \mathrm{s}$ (in a $10 \mathrm{~min}$ average) but we consider a prospective wind turbine at $90 \mathrm{~m}$ then our maximum mean wind speed at $90 \mathrm{~m}$ was $42.9 \mathrm{~m} / \mathrm{s}(37.287 \mathrm{~m} / \mathrm{s}$ in 1-hour average, table 3$)$ recorded during Hurricane Maria on September $20^{\text {th }} 2017$ as we can see in the highest peak in figure 5, where we plot a time series graph for the period under study. Also, we got the highest wave recorded was $6.4 \mathrm{~m}$.
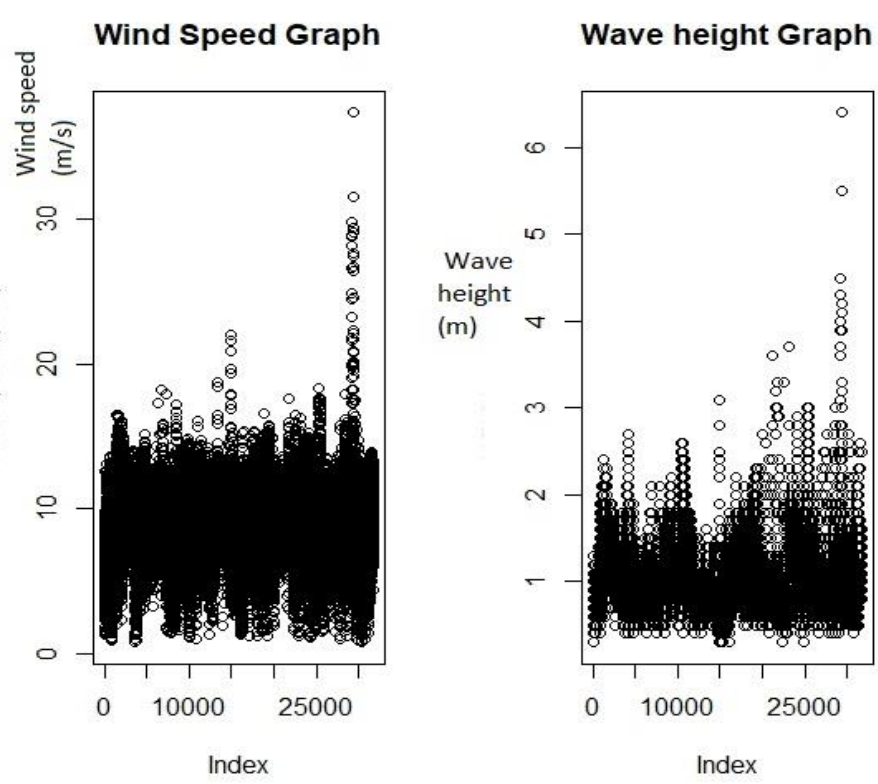

Fig. 5 Wind speed and Wave Height time series October 2013 - December 2017

Identically, the target site has a mean wind speed of 8.82 $\mathrm{m} / \mathrm{s}$ and mean wave height of $1.0 \mathrm{~m}$ during under period of study. Table 3 shows highest values recorded during Hurricane María (20 Sept.) and Hurricane Irma (6 Sept) where it is used a 1-hour average. Without difficulty, we can appreciate the hardness of the forces of nature during a climatic phenomenon for both wind speed and wave height.

\begin{tabular}{|l|l|l|l|l|l|l|}
\hline YY & MM & dd & hh & $\begin{array}{l}\text { Mean } \\
\text { Wind } \\
\text { Speed } \\
(\mathrm{m} / \mathrm{s})\end{array}$ & $\begin{array}{l}\text { Wind } \\
\text { Direction } \\
\left({ }^{\circ}\right)\end{array}$ & $\begin{array}{l}\text { Wave } \\
\text { Height } \\
(\mathrm{m})\end{array}$ \\
\hline 2017 & 9 & 6 & 19 & 28.810 & 285.33 & 3.9 \\
\hline 2017 & 9 & 20 & 6 & 29.018 & 36.33 & 4.2 \\
\hline 2017 & 9 & 20 & 11 & 29.331 & 128.00 & 5.5 \\
\hline 2017 & 9 & 6 & 20 & 29.773 & 257.50 & 4.0 \\
\hline 2017 & 9 & 20 & 7 & 31.515 & 38.66 & 5.5 \\
\hline 2017 & 9 & 20 & 8 & 37.287 & 61.00 & 6.4 \\
\hline
\end{tabular}

Table 3. Highest values recorded for Wind Speed at $90 \mathrm{~m}$.

Because we have Cumulative Distributions then to plot the Rayleigh density distribution, we need to derive the equation (6). First, we found that $\alpha$, estimated based on mean wind speed, was $9.19 \mathrm{~m} / \mathrm{s}$.

$1^{\text {th }}$ LACCEI International Multi-Conference for Engineering, Education, and Technology: "Innovation in Education and Inclusion", 19-21 July 2018, Lima, Peru. 


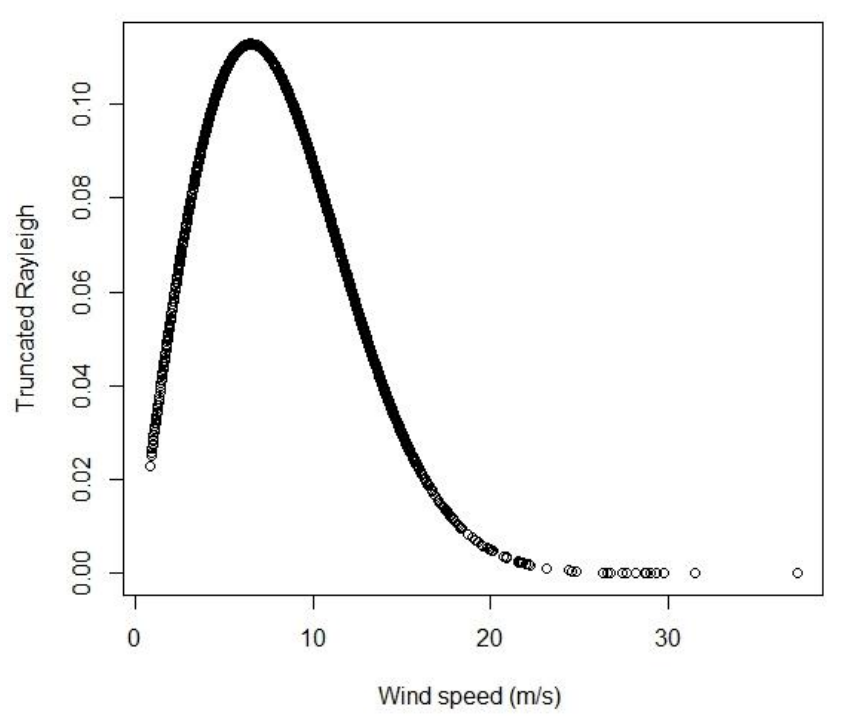

Fig. 6 Truncated Rayleigh density distribution

To calculate Weibull parameters shape $\mathrm{k}$ and scale $\eta$ we must use Maximum Likelihood Estimation (MLE) and obtain Weibull density function from equation (6).

Using a fitting function (see ref. [16]) to estimate these parameters, we get $\mathrm{k}=3.78$ and $\eta=9.83$. A graphic could be observed in Fig. 7.

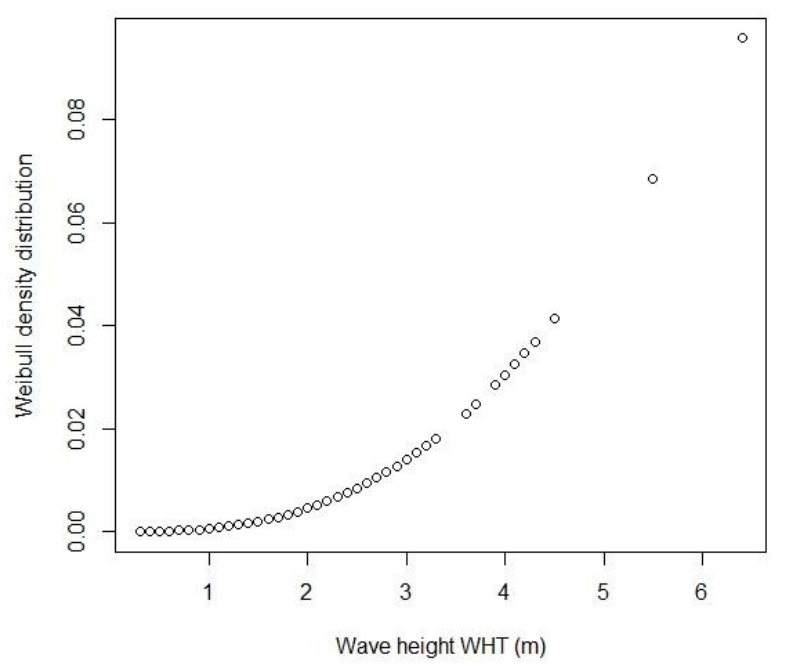

Fig. 7 Weibull density function for Wave height conditional on Wind Speed.

From eq. 8 and making use of fitdist function we calculated Gumbel parameters $\mathrm{u}=2.92$ and $\beta=3.34$ given $\left(V, H_{s}\right)$ data and we plot a density distribution graph as we see in figure 8 .

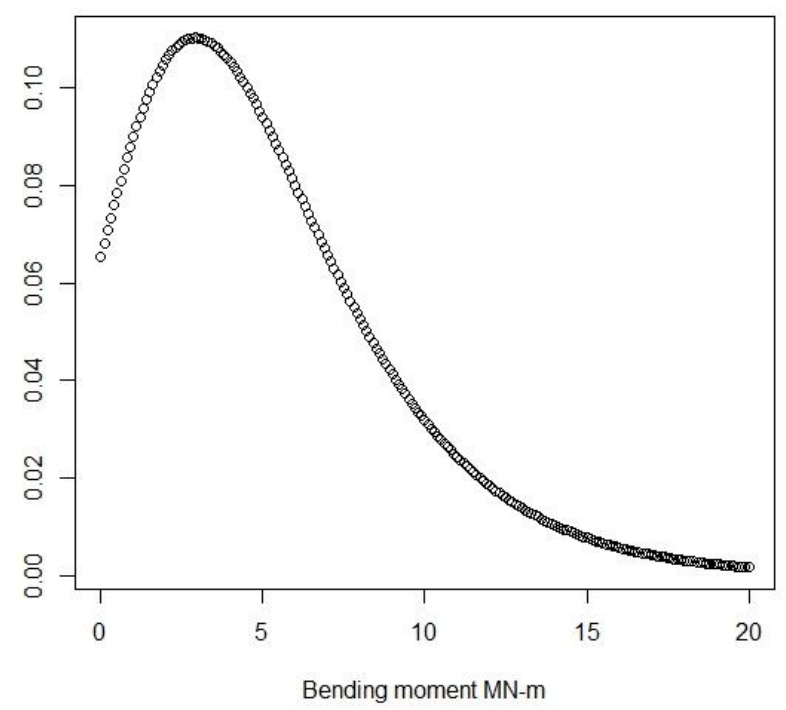

Fig. 8 Bending moment - Gumbel density distribution for normal conditions.

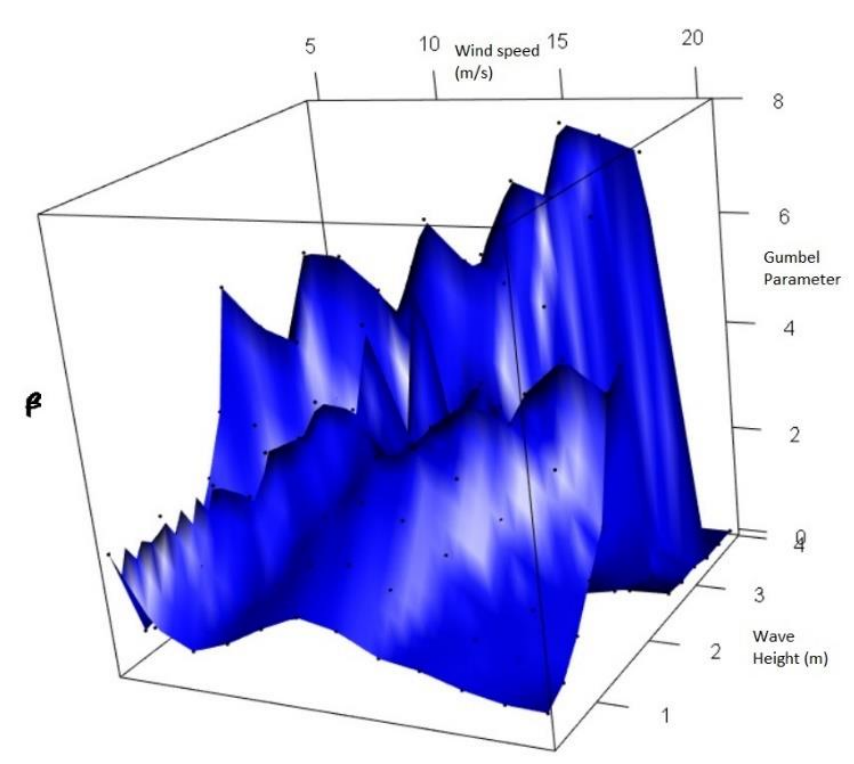

Figure 9. Variation Gumbel Parameter $\beta$

To calculate the long-term load $1_{\mathrm{T}}$, we must create a grid from Wind speed and Wave height and calculate every Gumbel parameters within each cell partition. We chose these ranges between intervals for Wind Speed $(4-20 \mathrm{~m} / \mathrm{s})$ and $(0.2-4.0$ $\mathrm{m})$ for Wave height because of being the most common values. Figure 9 shows a 3D graphic for Gumbel Parameter $\beta$ and its variations in our chosen grid.

The long-term load for a specified target probability may be estimated from the exceedance probability curve plotted in 
Fig. 10 making use of formula in eq. 9 . We use $\Delta V=1.5 \mathrm{~m} / \mathrm{s}$ and $\Delta H_{s}=0.3 \mathrm{~m}$, as we commented in paragraph B. Also, we consider $N_{H}=14$ and $N_{v}=12$. i.e. 168 cells to evaluate the summation.

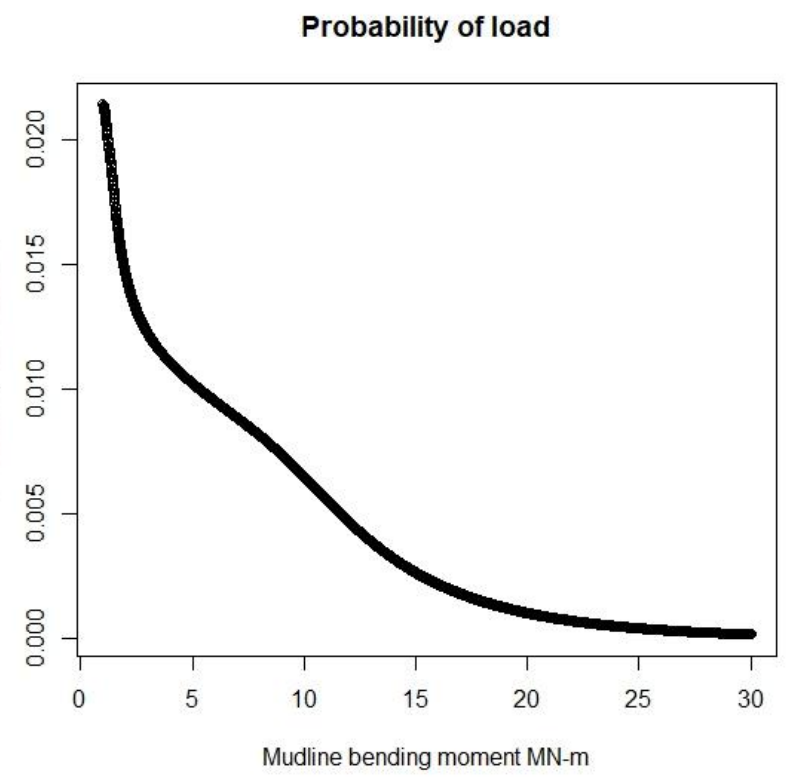

Fig. 10 Mudline bending moment load L versus Probability of exceedance $\mathrm{P}_{\mathrm{T}}$

From figure 10 we can observe the curve for exceedance probability values for a given Mudline bending moment. This graph says that we would expect low values of bending moments for a prospective wind turbine, but certain high values could occur throughout its useful life and we must calculate this possibility. The long-term probability of exceedance a Bending Moment Load of $29.46 \mathrm{MN}-\mathrm{m}$ is less than 0.0002 and the probability for a Load $39.35 \mathrm{MN}-\mathrm{m}$ is less than 0.00004 .

\section{CONCLUSIONS}

- In the present study, an evaluation of seven methods for the long-term prediction of the wind resource, known as MCP methods, has been conducted. Based on the most accurate measure-correlate-predict methods, multiple sectors and variance ratio, we predicted a maximum wind speed would be between $25 \mathrm{~m} / \mathrm{s}$ and $28 \mathrm{~m} / \mathrm{s}$, remarking this as a very solid and important result given that the period of study involved more than 30 years where several hurricanes made their presence in Puerto Rico.

- The highest wind speed recorded at Maria at $10 \mathrm{~m}$ was $31.3 \mathrm{~m} / \mathrm{s}$. This is, comparing with our analysis there was a error of prediction of $10 \%$. But, in 1-hour average analysis our best MCP methods yielded long- term values with less than $7 \%$ of error for mean wind speed and less than 3\% for standard deviation predictions.

- Since no MCP method achieved the initial requirements of fitting, we had to be cautious to use these results with high confidence for predicting maximum wind speed for the candidate site.

- We have used a statistical load extrapolation procedure to estimate long-term extreme loads for an offshore wind turbine. The mean wind speed at the possible nacelle height and the significant wave height were used to describe the environment in the candidate site, while the mudline bending moment was used to describe the turbine load of interest. Short-term distributions for the turbine load conditional on the environmental variables were modelled using parametric distributions.

- Given the enough data in consideration (193,459 data points) in addition to recent events that have happened and applying bootstraps techniques the long-term mean wind speed at $90 \mathrm{~m}$ for the target site is $8.94 \mathrm{~m} / \mathrm{s}$ for a 1-hour average and $8.82 \mathrm{~m} / \mathrm{s}$ for a $10 \mathrm{~min}$ average.

- Predicting mean wind speed and standard deviation with MCP methods at $90 \mathrm{~m}$ for a 1-hour average, they were being $8.35 \mathrm{~m} / \mathrm{s}$ and 2.46 respectively. it is not a bad prediction since as we saw before the values of the last 4 years are close to these results.

- The main limitation found in this study was to determine a reference station with more than 20 year of time series data and with high correlation (>0.9) with the target site and with similar environmental conditions.

\section{Recommendation}

- Given that there no exists a real wind turbine already installed it is necessary to simulate load conditions under operation. That is why a suggestion would be install an infrastructure to record bending load data.

- Given the amount of information provided during Hurricane Maria, we recommend more research on other reliable infrastructure calculation methods to protect investments and not fall back into the harsh conditions suffered during the disaster.

$1^{\text {th }}$ LACCEI International Multi-Conference for Engineering, Education, and Technology: "Innovation in Education and 


\section{REFERENCES}

\section{ACKNOWLEDGMENT}

This material is based upon work supported by the Department of Energy / National Nuclear Security Administration under Award number DE-NA0003330.

\section{NOMENCLATURE}

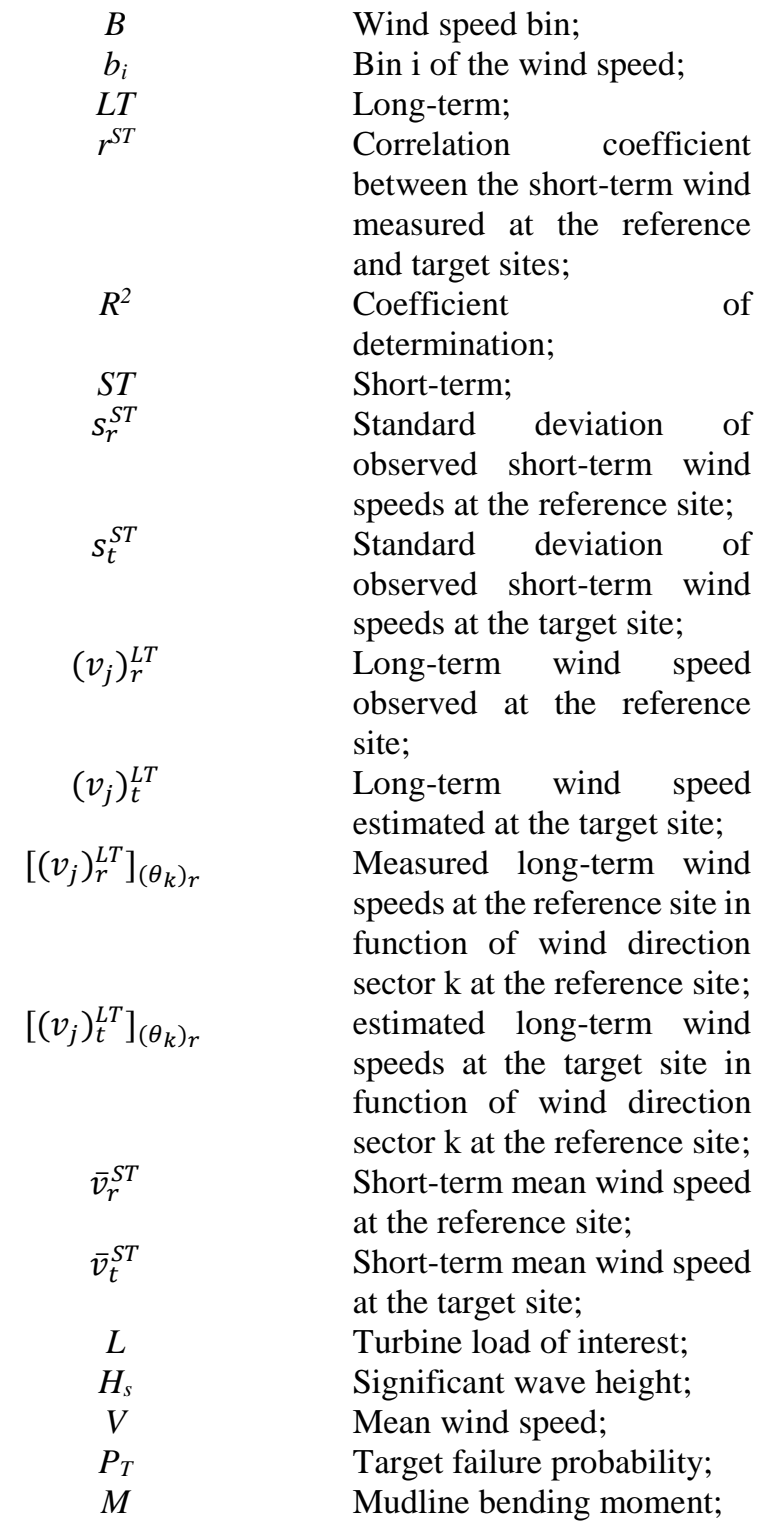

[1] National Wheater Service. Major Hurricane Maria - September 20, 2017. [Online]. Available: https://www.weather.gov/sju/maria2017 [Accessed March 5, 2018]

[2] FEMA. Hurricane Maria. [Online] Available: https://www.fema.gov/hurricane-maria [Accessed 5 March 2017]

[3] L. Greenemeier. Repair or Renovate? Puerto Rico Faces Stark Power Grid Options. [Online] Available:

https://www.scientificamerican.com/article/repair-or-renovate-puertorico-faces-stark-power-grid-options/ [Accesed 5 March 2017]

[4] H. Rodríguez, G. Carbajal and E. Romero, "Preliminary cost assessment for offshore wind energy in Puerto Rico," in XIII Latin American and Caribbean Conference for Engineering and Technology, Santo Domingo, Dominican Republic, 2015.

[5] LexJuris, LexJuris Puerto Rico, 19 July 2010. [Online]. Available: http://www.lexjuris.com/lexlex/Leyes2010/lex12010082.htm. [Accessed 3 August 2017].

[6] A. Irizarrry, B. Colucci and E. O'Neill, "Achievable renewable energy targets for Puerto Rico's renewable energy portfolio standard," Puerto Rico Energy Affairs, 2008

[7] H. Rodríguez, N. Gómez and R. Morales, "Benthic habitat considerations for an offshore wind farm site selection in Puerto Rico," in XIV Latin American and Caribbean Conference for Engineering and Technology, San José, Costa Rica, July 2016.

[8] National Data Buoy Center. Station 41056 Historical Data. [Online] Available: http://www.ndbc.noaa.gov/station_history.php?station=41056 [Accessed 5 March 2017].

[9] Wave Information Studies. [Online] Available: http://wis.usace.army.mil/hindcasts.html?dmn=atlantic [Accessed 3 August 2017].

[10]J. Carta, S. Velázquez and P. Cabrera, "A review of measure-correlatepredict (MCP) methods used to estimate long-term wind characteristics at a target site," Renewable and Sustainable Energy Reviews, vol. 27, pp 362400, November 2013.

[11]A. Rogers, J. Rogers and J. Manwell, "Comparison of the performance of four measure-correlate-predict algorithms," Journal of Wind Engineering and Industrial Aerodynamics, March 2005.

[12]P. Romo, J. Amezcua and O. Probst, "Validation of three new measurecorrelate predict models for the long-term prospection of the wind resource," Journal of Renewable and Sustainable Energy, vol. 3, pp 1-20, April 2011.

[13]Jerome Friedman, Trevor Hastie, Robert Tibshirani. Regularization Paths for Generalized Linear Models via Coordinate Descent. Journal of Statistical Software, 33(1), 1-22. (2010)

[14] C. Skittides and W. Früh1. A new Measure-Correlate-Predict Wind Resource Prediction method. International. Conference on Renewable Energies and Power Quality (ICREPQ'15). La Coruña (Spain), 25th to 27th March 2015. ISSN 2172-038 X, No.13, pp 612-613. April 2015.

[15] P. Agarwal, L. Manuel, "Extreme loads for an offshore wind turbine using statistical extrapolation from limited field data," Wind Energy, vol. 11, pp 673-684, November 2008.

[16] M. Delignette-Muller, C. Dutang. fitdistrplus: An R Package for Fitting Distributions. Journal of Statistical Software, 64(4), 1-34. URL http://www.jstatsoft.org/v64/i04/. (2015)

16 $^{\text {th }}$ LACCEI International Multi-Conference for Engineering, Education, and Technology: "Innovation in Education and 